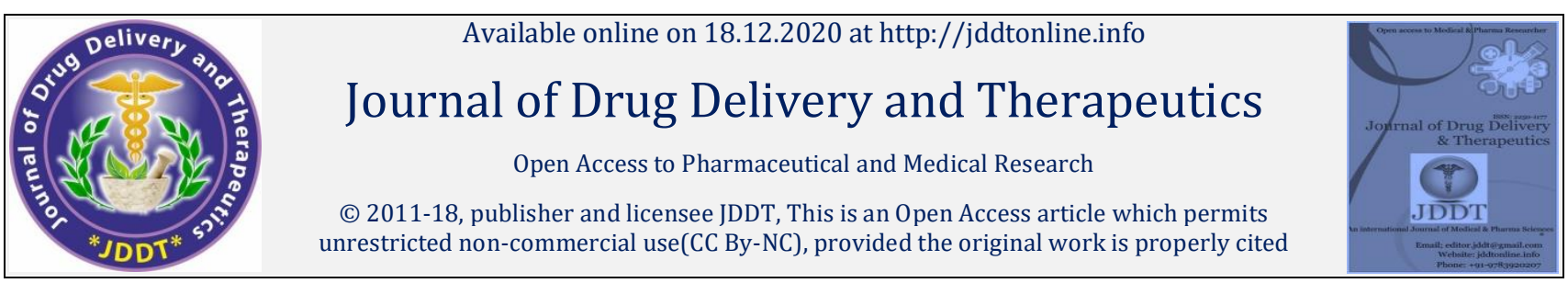

Open $\odot$ Access

Research Article

\title{
The Association of Clinicopathological Features with Metastatic Status in Infiltrative Urothelial Carcinoma of Bladder
}

\author{
*Siska Dwiyantie Wahyuni, Sri Suryanti, Hasrayati Agustina, Bethy Suryawathy Hernowo \\ Anatomical Pathology Department Faculty of Medicine University of Padjadjaran/Hasan Sadikin Hospital Bandung, Indonesia
}

\begin{abstract}
Background: Infiltrative urothelial carcinoma of bladder is an aggressive variant of bladder carcinoma. Most of the patients in their first encounter with doctors are diagnosed with advanced stages and many has metastasized. Metastasis is a process of malignant tumor cells migrating from its primary tumor location to other organs or sites inside the body via blood circulation or lymphatic system. Metastasis process is responsible for $90 \%$ cancer deaths compared to the primary tumor itself, infiltrative urothelial carcinoma of bladder. To reduce mortality, knowledge of the clinicopathological characteristics associated with metastasis is needed.
\end{abstract}

Method: Research material used was clinical data and paraffin block from patients with metastatic and non-metastatic infiltrative urothelial carcinoma of bladder. Clinical data taken from Central Medical Record Installation and Urology Medical Record Installation Padjadjaran University/ Dr. Hasan Sadikin Hospital Bandung, Indonesia. Paraffin blocks were obtained from operations at Hasan Sadikin Hospital Bandung, Indonesia.Total data sample obtained were 40 samples, 20 samples are metastatic and another 20 are non-metastatic samples. Clinicopathological parameters included in the analysis were age, sex and pathalogical T stage.

Result: Pathalogical T stage have associations with metastatic status with significant result with $\mathrm{p}$ value $=0.035$ ( $\mathrm{p}<0.005)$.

Conclusion: Pathalogical $\mathrm{T}$ stage was associated with the metastatic status of Infiltrative urothelial carcinoma of bladder and may play important roles during the metastatic process. Thus, it can be used as a predictor factor for the infiltrative urothelial carcinoma of bladder.

Keywords: infiltrative urothelial carcinoma of bladder, metastastic, pathalogical T stage

Article Info: Received 11 Oct 2020; $\quad$ Review Completed 27 Nov 2020; $\quad$ Accepted 08 Dec 2020; $\quad$ Available online 18 Dec 2020

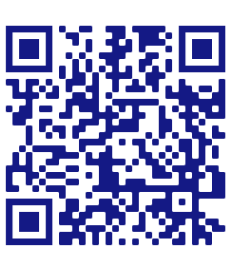

Cite this article as:

Wahyuni SW, Suryanti S, Agustina H, Hernowo BS, The Association of Clinicopathological Features with Metastatic Status in Infiltrative Urothelial Carcinoma of Bladder, Journal of Drug Delivery and Therapeutics. 2020; 10(6-s):99-102 http://dx.doi.org/10.22270/jddt.v10i6-s.4647

Siska Dwiyantie Wahyuni, Anatomical Pathology Department Faculty of Medicine University of Padjadjaran/Hasan Sadikin Hospital Bandung, Indonesia

\section{INTRODUCTION}

Worldwide, bladder cancer is the sixth most common malignancy in male and the seventeenth most common malignancy in female. Bladder cancer occupies the $13^{\text {th }}$ highest cancer in the world. ${ }^{1}$ According to GLOBOCAN 2018, there are 549.393 new cases of bladder cancer around the world with mortality rate of $199.922 .^{2}$ Although it can occur at a young age, more than $90 \%$ of cases occur at the age of $65-70$ years and most occur in men than women with a ratio of 3-4: 1 1, 3-5

Urothelial carcinoma (traditionally known as transitional cell carcinoma) is the most frequently occurring type of bladder cancer and accounting for $\sim 90 \%$ of all primary tumors in the urinary bladder. Infiltrative urothelial carcinoma of bladder is an aggressive variant of urothelial carcinoma is one of the leading causes of cancer related deaths worldwide. Bladder cancer-related mortality is associated with the development of metastatic potential of primary tumor lesions. Metastasis is a process of malignant tumor cells migrating from its primary tumor location to other organs or sites inside the body via blood circulation or lymphatic system. ${ }^{6}$ Metastatic process is responsible for $90 \%$ cancer deaths compared to the primary tumor itself, infiltrative urothelial carcinoma of bladder. ${ }^{7}$

Many prognostic factors for are known for infiltrative urothelial carcinoma of bladder and numerous prognostic models have been developed in an attempt to predict which patients ultimately will develop metastasis. The prognostic models include such variables as patient age, sex and pathological $\mathrm{T}$ stage to better predict outcome. ${ }^{3}$ Pathological T Stage (pT) is very important in determining 
prognosis so that the reporting of the TNM staging requires additional pathological information. The pT1 staging tumor has invaded the lamina propia but has not yet reached the muscularis propia. Usually forms a papillary structure, if it forms nodular or sessile it tends to invade deeper.4, 8 If the tumor has invaded the tunica muscularis propia, it means that the stage of the tumor is pT2. The tunica muscularis propia (detrusor muscle) can be seen as thick bundles of muscle fibers. Stage 2 is divided into pT2a (invades the inside of the muscularis propia) and pT2b (invades the outside of the muscularis propia). Stage pT3 when the tumor cells have invaded the fat tissue around the bladder and stage pT4 when the tumor cells have metastasized to other organs around the bladder. 4,9

In this study, infiltrative urothelial carcinoma of bladder cases diagnosed in 6 years was investigated retrospectively. The objective of this study was to describe the epidemiological and clinicopathologic characteristics of infiltrative urothelial carcinoma of bladder to identify the clinicopathologic variables associated with the metastasis. The results of this study are expected to be helpful in predicting metastasis in infiltrative urothelial carcinoma of bladder.

\section{MATERIAL AND METHODS}

The research material is paraffin blocks of patients who have undergone operation and has been diagnosed histopathological as infiltrative urothelial carcinoma of bladder period between 1 January 2014-April 2020. Paraffin blocks were taken from the Departement of Anatomical Pathology in Dr. Hasan Sadikin Hospital. Clinicopathological parameters included in the analysis were: age, sex and pathological T stage. Clinical data taken from Central Medical Record Installation and Urology Medical Record Installation Padjadjaran University/ Dr. Hasan Sadikin Hospital Bandung, Indonesia. Total data sample obtained were 40 samples, 20 samples are metastatic and another 20 are non-metastatic samples.

\section{RESULTS}

\section{Patient's characteristics}

In this study, total samples are 40, 20 samples are metastatic and another 20 are non-metastatic samples.

\section{Characteristics of Research Subjects}

Table 1: Characteristics of Research Subjects

\begin{tabular}{ll}
\hline Variable & $\mathbf{N}=\mathbf{4 0}$ \\
\hline $\begin{array}{l}\text { Age (year) } \\
\text { Mean+Std }\end{array}$ & $57.76 \pm 11.088$ \\
Sex & \\
Male & $36(90 \%)$ \\
Female & $4(10 \%)$ \\
Pathalogical T stage & \\
pT1 & \\
pT2 & $0(0 \%)$ \\
pT3 & $7(17.5 \%)$ \\
pT4 & $16(40 \%)$ \\
\hline
\end{tabular}

Table 1 shows the characteristics of research subjects based on age, gender and pathological T stage. The average age of the subjects is 58 years old. The most common sex found in this study is male, as many as 36 subjects (90\%). The most pathological T stage found was T4 with 17 subjects $(42.5 \%)$.

Table 2: Comparison of the Characteristics of Research Subjects based on the Metastatic and Non-Metastatic Status groups

\begin{tabular}{|c|c|c|c|}
\hline \multirow{3}{*}{ Variable } & \multicolumn{2}{|c|}{ Metastatic Status } & \multirow{3}{*}{ p value } \\
\hline & Metastatic & Non Metastatic & \\
\hline & $\mathbf{N}=\mathbf{2 0}$ & $\mathbf{N}=\mathbf{2 0}$ & \\
\hline
\end{tabular}

\section{Age (year)}

Mean \pm Std

$57.30 \pm 8.392$

Sex

Male

Female

18(90\%)

$2(10 \%)$

$58.25 \pm 13.471$

0,790

1,000

18(90.0\%)

$2(10.0 \%)$

Pathological T Stage

$\begin{array}{lc}\text { pT1 } & 0(0 \%) \\ \text { pT2 } & 1(5 \%) \\ \text { pT3 } & 6(30 \%) \\ \text { pT4 } & 13(65 \%)\end{array}$

0,035*

$$
0(0 \%)
$$$$
6(30 \%)
$$

$4(20 \%)$ 
Note: Numerical data for age were tested using unpaired t test. Data categorical gender and stage T were tested using Fisher's exact test, $*$ p value $<0.05$ means significant or statistically significant.

Table 2 describes the comparison of characteristics by age, sex, and pathological $\mathrm{T}$ stage in the metastatic and nonmetastatic groups.

Based on the above analysis, there was no difference in the mean age of both the metastatic and non-metastatic groups. The statistical test results obtained p value $=0.790(>0.05)$ which means not significant or not statistically significant.

There was no difference in the proportion of sex in the metastatic and non-metatastic groups. The statistical test results showed that the value of $p=1,000(>0.05)$ which means it is not significant or not statistically significant.

There was a difference in the proportion of pathological $\mathrm{T}$ stage in the metastatic and non-metastatic groups. The results of statistical tests obtained p value $=0.035(<0.05)$ which means significant or statistically significant, thus it can be explained that there is a statistically significant difference in percentage between the pathological $\mathrm{T}$ stage variable in the metastatic and non-metastatic groups.

\section{DISCUSSION}

Infiltrative urothelial carcinoma of bladder is an aggressive form of bladder carcinoma with its incidence keeps rising every year. When diagnosed, more than $70 \%$ patients come with advanced stadium and more than $50 \%$ have developed metastasis. Metastatic infiltrative urothelial carcinomas of bladder have limited therapy options. Despite its sensitivity to chemotherapy, most of the patients are resistant and end up with deaths. Thus, the 5 years survival rate of infiltrative urothelial carcinoma of bladder is very low or only around 5 $\% .1,2$

Based on age, the mean age in this study is 58 years old (fifth decade). This is consistent with study conducted by Kalyan Saginal et. al. that showed bladder carcinoma mostly affected people in their fifth decade. Ninety\% of new bladder cancer diagnoses in the US are in people 55 years of age or older, and the average age of diagnosis is 73 . The chances of being diagnosed with bladder cancer increases with age. More than $70 \%$ of people with bladder cancer are older than 65.1 Meanwhile, according to WHO, the incidence of infiltrative urothelial carcinoma of bladder has increased in the $6^{\text {th }} 7^{\text {th }}$ decade. ${ }^{3}$

Based on sex, more male than female found in this study. This is also consistent with study conducted by Kalyan Saginala et. al. and WHO that stated infiltrative urothelial carcinoma of bladder affecting more male than female with ratio of 4:1 and 3-4:1 respectively. ${ }^{1,3}$ In this study, the ratio of male to female is 19:1. This is probably caused by consecutive sampling used as sample collection technique in this study. The gender disparity in bladder cancer risk is readily evident considering men represent slightly more than $75 \%$ of new diagnoses each year. Perhaps the most obvious explanation for this difference is the inequality in exposure to bladder carcinogens, namely tobacco smoke. This topic has undergone close examination but higher rates of smoking and tobacco use among males fails to entirely account for the increased bladder cancer risk. Sex hormones may play a key role in the development and progression of bladder cancer, with increased androgen receptor expression noted in lower stage/grade tumors while higher stage disease is associated with increased expression of the estrogen receptor $\beta$ isoform. This may point to an explanation for the poorer stage-adjusted cancer-specific mortality in women compared to men (HR 1.17-4.47) in spite of a male to female incidence ratio of 4 to 1 . Internationally, gender differences in bladder cancer mirrors the trends seen in the US population but incidences vary widely from region to region. For instance, the lowest age-standardized rates (ASR) in men are seen in Africa (Uganda ASR $=2.6$ per 100,000 ) while the highest are found in North America (ASR $=19.5$ per 100,000) and Europe (ASR = 17.7 per 100,000), including Spain with its ASR of 36.7 per 100,000 men. ${ }^{10}$

Based on pathalogical T stage, higher stadiums were found more on metastatic group. This is also consistent with a study conducted by Yu li et. al. stated that bladder carcinoma progressivity is parallel to the increased of clinical stages. ${ }^{11}$ A study by Sung Han Kim et al said that pathological T stage is useful for risk stratification, as higher pathological stage are associated with poor prognoses. ${ }^{12} \mathrm{~A}$ study by Reis et al also stated that increased stadium in bladder carcinoma can be used as prognostic marker. ${ }^{13}$ In a study conducted by Retz et. al. was found that bladder carcinoma progressivity correlates with potential of migration and metastasis $(p=0,018) .{ }^{14}$ Based on study by Li et. al., T stage is a more important factor than $\mathrm{N}$ and $\mathrm{M}$ stage in the prognosis of colorectal cancer. ${ }^{15}$ Study conducted by Yousef stated that TNM stage affects breast cancer progressivity. ${ }^{16}$

\section{CONCLUSION}

In our study was found there is a significant association between pathological $\mathrm{T}$ stage and metastatis of infiltrative urothelial carcinoma of bladder where the staging are, the higher the probability of metastasis to occur in infiltrative urothelial carcinoma of bladder.

\section{ACKNOWLEDGMENTS}

The authors would like to thank to technicians of histopathology, archivists of Central Medical Record Installation and Urology Medical Record Installation Padjadjaran University/ Dr. Hasan Sadikin Hospital Bandung, Indonesia for all technical support.

\section{CONFLICT OF INTEREST}

The authors declare that there are no conflict of interests in this study.

\section{REFERENCES}

1. Saginala K, Barsouk A, Aluru JS, Rawla P, Padala SA, Barsouk A. Epidemiology of Bladder Cancer. Medical sciences (Basel, Switzerland). 2020 Mar 13; 8(1).

2. Bray F, Ferlay J, Soerjomataram I, Siegel RL, Torre LA, Jemal A. Global cancer statistics 2018: GLOBOCAN estimates of incidence and mortality worldwide for 36 cancers in 185 countries. CA: a cancer journal for clinicians. 2018 Nov; 68(6):394-424.

3. Fred T. Bosman MP ESJM, Sunil R.Lakhani MF, Hiroko Ohgaki. P.Tumours of the urinary tract. In: Holger Moch PAH, Thomas M.U I bright, Victor E.Reuter (Eds), editor. WHO Classification of Tumours of the Urinary System and Male Genital Organs.4 ed.Lyon, France: International Agency for Research on Cancer (IARC) Press: International Agency for Research on Cancer (IARC) Press; 2016.hlm.77-106. 2016; 77-106.

4. Cheng L, Lopez-Beltran A, Bostwick DG. Bladder Pathology: John Wiley \& Sons; 2012.

5. Miyazaki J, Nishiyama H. Epidemiology of urothelial carcinoma. International journal of urology : official journal of the Japanese Urological Association. 2017 Oct; 24(10):730-4.

6. Arvelo F, Sojo F, Cotte C. Tumour progression and metastasis. Ecancermedicalscience. 2016; 10:617. 
7. Fares J, Fares MY, Khachfe HH, Salhab HA, Fares Y. Molecular principles of metastasis: a hallmark of cancer revisited. Signal Transduction and Targeted Therapy. 2020 2020/03/12; $5(1): 28$.

8. Otsuka M, Taguchi S, Nakagawa T, Morikawa T, Maekawa S, Miyakawa J, et al. Clinical significance of random bladder biopsy in primary $\mathrm{T} 1$ bladder cancer. Mol Clin Oncol. 2018 2018/05/01; 8(5):665-70.

9. Amin MB, Epstein JI, Reuter VE. Biopsy interpretation of the bladder. Philadelphia, PA: Wolters Kluwer; 2017.

10. Matulay JT KA. Epidemiology and Etiology of Bladder Cancer. Uro Today. 2019.

11. Li Y, Chen M, Yuan J, Zhou X, He W, Zu X, et al. CXCR4 Expression in Bladder Transitional Cell Carcinoma and Its Relationship with Clinicopathological Features. Urologia Internationalis. 2014; 92(2):157-63.

12. Kim SH, Song MK, Joung JY, Chung J, Lee KH, Seo HK. Significant clinicopathologic prognostic factors for bladder recurrence, progression, and cancer-specific survival after surgery among patients with upper urinary tract urothelial carcinoma. Investigative and clinical urology. 2019 Nov; 60(6):432-42.

13. Reis ST, Leite KRM, Piovesan LF, Pontes-Junior J, Viana NI, Abe DK, et al. Increased expression of MMP-9 and IL-8 are correlated with poor prognosis of Bladder Cancer. BMC Urology. 2012 2012/06/13; 12(1):18.

14. Retz MM, Sidhu SS, Blaveri E, Kerr SC, Dolganov GM, Lehmann J, et al. CXCR4 expression reflects tumor progression and regulates motility of bladder cancer cells. 2004.

15. Li J, Guo BC, Sun LR, Wang JW, Fu XH, Zhang SZ, et al. TNM staging of colorectal cancer should be reconsidered by $\mathrm{T}$ stage weighting. World journal of gastroenterology. 2014 May 7; 20(17):5104-12.

16. Yousef EM, Tahir MR, St-Pierre Y, Gaboury LA. MMP-9 expression varies according to molecular subtypes of breast cancer. BMC cancer. 2014 Aug 23; 14:609. 